NASA/CR-2003-211825

\title{
A Study of Scaling for Intercycle Ice Accretion Tests
}

David N. Anderson

Ohio Aerospace Institute, Brook Park, Ohio

Galdemir C. Botura

B.F. Goodrich Aerospace, Uniontown, Ohio

Andy P. Broeren

University of Illinois at Urbana-Champaign, Urbana, Illinois 
Since its founding, NASA has been dedicated to the advancement of aeronautics and space science. The NASA Scientific and Technical Information (STI) Program Office plays a key part in helping NASA maintain this important role.

The NASA STI Program Office is operated by Langley Research Center, the Lead Center for NASA's scientific and technical information. The NASA STI Program Office provides access to the NASA STI Database, the largest collection of aeronautical and space science STI in the world. The Program Office is also NASA's institutional mechanism for disseminating the results of its research and development activities. These results are published by NASA in the NASA STI Report Series, which includes the following report types:

- $\quad$ TECHNICAL PUBLICATION. Reports of completed research or a major significant phase of research that present the results of NASA programs and include extensive data or theoretical analysis. Includes compilations of significant scientific and technical data and information deemed to be of continuing reference value. NASA's counterpart of peerreviewed formal professional papers but has less stringent limitations on manuscript length and extent of graphic presentations.

- TECHNICAL MEMORANDUM. Scientific and technical findings that are preliminary or of specialized interest, e.g., quick release reports, working papers, and bibliographies that contain minimal annotation. Does not contain extensive analysis.

- CONTRACTOR REPORT. Scientific and technical findings by NASA-sponsored contractors and grantees.
- CONFERENCE PUBLICATION. Collected papers from scientific and technical conferences, symposia, seminars, or other meetings sponsored or cosponsored by NASA.

- SPECIAL PUBLICATION. Scientific, technical, or historical information from NASA programs, projects, and missions, often concerned with subjects having substantial public interest.

- TECHNICAL TRANSLATION. Englishlanguage translations of foreign scientific and technical material pertinent to NASA's mission.

Specialized services that complement the STI Program Office's diverse offerings include creating custom thesauri, building customized data bases, organizing and publishing research results ... even providing videos.

For more information about the NASA STI Program Office, see the following:

- Access the NASA STI Program Home Page at http://www.sti.nasa.gov

- E-mail your question via the Internet to help@sti.nasa.gov

- Fax your question to the NASA Access Help Desk at 301-621-0134

- Telephone the NASA Access Help Desk at 301-621-0390

- Write to:

NASA Access Help Desk

NASA Center for AeroSpace Information 7121 Standard Drive

Hanover, MD 21076 
NASA/CR-2003-211825

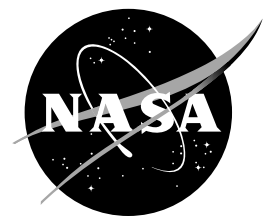

\section{A Study of Scaling for Intercycle Ice Accretion Tests}

David N. Anderson

Ohio Aerospace Institute, Brook Park, Ohio

Galdemir C. Botura

B.F. Goodrich Aerospace, Uniontown, Ohio

Andy P. Broeren

University of Illinois at Urbana-Champaign, Urbana, Illinois

Prepared for the

39th Aerospace Sciences Meeting and Exhibit

sponsored by the American Institute of Aeronautics and Astronautics

Reno, Nevada, January 8-11, 2001

Prepared under Cooperative Agreement NCC3-884

National Aeronautics and

Space Administration

Glenn Research Center 


\section{Acknowledgments}

The study reported here was jointly supported by the FAA, NASA, and B.F. Goodrich. The authors wish to thank Jim Riley and Gene Hill of the FAA, Gene Addy of NASA, and Dave Sweet of B.F. Goodrich for their guidance during the planning of the tests and for their support and direction during the course of the study. In addition, Tim Hawk of NASA, Manny Rios and Chris Dumont of the FAA, and Pete Brown, Jerry Hansard, and Jason McHood of B.F. Goodrich provided invaluable assistance during the execution of the tests.

This report contains preliminary

findings, subject to revision as analysis proceeds.

The Aerospace Propulsion and Power Program at NASA Glenn Research Center sponsored this work.

Available from

NASA Center for Aerospace Information 7121 Standard Drive

Hanover, MD 21076
National Technical Information Service 5285 Port Royal Road Springfield, VA 22100 


\title{
A STUDY OF SCALING FOR INTERCYCLE ICE ACCRETION TESTS
}

\author{
David N. Anderson* \\ Ohio Aerospace Institute \\ Brook Park, Ohio 44142 \\ Galdemir C. Botura ${ }^{\dagger}$ \\ BFGoodrich Aerospace \\ Uniontown, Ohio 44685 \\ Andy P. Broeren* \\ University of Illinois at Urbana-Champaign \\ Urbana, Illinois 60680
}

\begin{abstract}
$\underline{\text { Abstract }}$
The Ruff method with matched scale and reference velocity was used to determine appropriate $1 / 2$-scale test conditions to simulate a full-size icing encounter for an NACA 23012 wing section protected with a pneumatic boot de-icing system. Intercycle ice accretions were recorded on a 36-in.-chord model used to represent $1 / 2$ scale and compared with a hybrid reference model (fullsize leading-edge and truncated aft section) representing a 72-in.-chord full-size airfoil. The intercycle ice thickness and extent of icing for the scale tests generally compared well with those from the reference model. However, the scale tests did not reproduce the location and number of feather rows seen in the reference tests aft of the main ice shape. Many of the differences observed were believed to result from not scaling the pneumatic boot design along with the model size for these tests.
\end{abstract}

\section{Nomenclature}

$A_{c} \quad$ Accumulation parameter, dimensionless

$b \quad$ Relative heat factor, dimensionless

$c \quad$ Model chord, in.

$c_{p} \quad$ Specific heat of air, Btu/lbm ${ }^{\circ} \mathrm{R}$

$c_{p, w s} \quad$ Specific heat of water at the surface temperature, Btu/lbm ${ }^{\circ} \mathrm{R}$

$h_{c} \quad$ Convective heat transfer coefficient, $\mathrm{Btu} / \mathrm{hr} \mathrm{ft}^{2}{ }^{\circ} \mathrm{R}$

$h_{G} \quad$ Gas-phase mass transfer coefficient, $\mathrm{lbm} / \mathrm{hr} \mathrm{ft}^{2}$

\footnotetext{
* Senior Research Associate, Member AIAA

${ }^{\dagger}$ Senior Product Engineer, R\&D, De-icing and Specialty Systems Division, Member AIAA

* Post-Doctoral Research Associate, Department of Aeronautical and Astronautical Engineering, Member AIAA
}

$k \quad$ Thermal conductivity of air, Btu/hr $\mathrm{ft}{ }^{\circ} \mathrm{R}$

$K_{0} \quad$ Modified inertia parameter, dimensionless

$L W C \quad$ Cloud liquid-water content, $\mathrm{g} / \mathrm{m}^{3}$

$M V D \quad$ Water droplet median volume diameter, $\mu \mathrm{m}$

$n \quad$ Freezing fraction, dimensionless

$p \quad$ Static pressure, $\mathrm{psi}$

$p_{w} \quad$ Vapor pressure of water in the atmosphere, psi

$p_{w w} \quad$ Vapor pressure of water over liquid water, psi

$\mathrm{Pr} \quad$ Prandtl number, dimensionless

$r \quad$ Recovery factor, dimensionless

$r_{l e} \quad$ Leading-edge radius of airfoil, in.

Re Reynolds number of model, dimensionless

$S \quad$ Chordwise distance from leading edge, in.

$t_{f} \quad$ Freezing temperature of water, $0^{\circ} \mathrm{F}$

$t_{s} \quad$ Surface temperature, ${ }^{\circ} \mathrm{F}$

$t_{s t} \quad$ Static temperature, ${ }^{\circ} \mathrm{F}$

$V \quad$ Air velocity, mph

$\alpha \quad$ Angle of attack, ${ }^{\circ}$

$\beta \quad$ Local collection efficiency, dimensionless

$\beta_{0} \quad$ Collection efficiency at stagnation line, dimensionless

$\theta \quad$ Air energy transfer terms in energy balance, ${ }^{\circ} \mathrm{F}$

$\kappa \quad$ Constant exponent in equation (1)

$\Lambda_{f} \quad$ Latent heat of freezing, Btu/lbm

$\Lambda_{v} \quad$ Latent heat of vaporization, Btu/lbm

$\rho_{l} \quad$ Ice density, $\mathrm{lbm} / \mathrm{ft}^{3}$

$\tau \quad$ Accretion time, min

$\phi \quad$ Droplet energy transfer terms in energy balance, ${ }^{\circ} \mathrm{F}$

Subscripts

$R \quad$ Reference conditions

$S \quad$ Scale conditions

\section{Introduction}

To minimize test-section blockage in icing tunnels, it is often necessary to scale the test model. Two approaches to scaling are: size scaling, in which the entire model is geometrically reduced in size while maintaining the same non-dimensional shape, and 
hybrid scaling, in which a full-size leading edge is attached to a truncated after body.

For size scaling, methods are required to determine scaled test conditions that will simulate the full-scale icing encounter and produce the same non-dimensional ice shape. Similarity parameters ${ }^{1,2}$ have been identified which best describe the important phenomena of icing physics, including the flowfield approaching and around the model, the droplet trajectories, the quantity of ice accumulation, and the surface heat balance. Each of the commonly used scaling parameters will be described below.

For hybrid scaling, the after body is designed so that the flow around the leading edge and the droplet impingement characteristics reproduce those of the fullscale airfoil. Consequently, the test conditions used for the hybrid-scaled test simply match the full-size (reference) conditions. The hybrid airfoil is more attractive for testing than the full-size model since the actual chord length is less than the equivalent full-scale airfoil. This reduces potential problems associated with model blockage, mounting, weight, fabrication cost, etc.

The pneumatic boot de-icing system works by periodically inflating tubes made of an elastic material to break and shed the intercycle ice accreted since the last activation. To be successful, scaled tests should provide a good simulation (relative to the airfoil size) of the intercycle ice quantity, location and size of protrusions and icing limits for given icing situations.

In the present series of tests, scaling was applied for both size scaling and hybrid scaling based on a full-size model of an NACA 23012 airfoil with a 72-in. chord. Tests were made in the BFGoodrich Aerospace Deicing and Specialty Systems Division (DSSD) Icing Wind Tunnel (IWT). The full-size airfoil would have been too large to be tested in this facility, so the hybridscaled model with a full-size leading edge served as the reference model. The scale test used a 36-in.-chord NACA 23012 model with the scaled test conditions determined from the reference values by applying the Ruff scaling method using constant velocity. Both size scaling and hybrid scaling methods will be described in this paper along with model descriptions and experimental ice shapes recorded in the tests.

\section{$\underline{\text { Size Scaling }}$}

\section{$\underline{\text { Scaling Parameters }}$}

One goal in testing models with the size reduced from the desired reference dimensions, is to produce accreted ice-shapes whose coordinates are non-dimensionally the same as would have been obtained with the reference test. To do this, similarity of the physics of ice accretion has to be assured in these areas: the flowfield around the model, droplet trajectories, total water catch and, for glaze ice, heat balance on the surface. Similarity of water-film phenomena may also need to be satisfied for glaze ice, ${ }^{3}$ but these will not be discussed here.

The flowfield can be simulated by using a model that is dimensionally similar to the full-scale (reference) article, by using the same angle of attack and by matching scale and reference values of $\operatorname{Re}$ and $M$. For icing encounters, the speeds involved are usually low enough that $M$ should have little effect and is neglected. $R e$ is usually ignored as well by arguing that any ice accretion will trip the boundary layer and the flow will then be independent of $R e$.

Similarity of droplet trajectories and, therefore, droplet collection efficiencies, can be obtained by matching the modified inertia parameter, $K_{0}$, of Langmuir and Blodgett. ${ }^{4}$ An exact determination of $K_{0}$ is somewhat involved, but it can be approximated using:

$$
K_{0}=(\text { constant }) \frac{M V D^{2-\kappa} V^{1-\kappa}}{2 r_{l e} p^{\kappa}}
$$

where $\kappa$ is a constant and $r_{l e}$ is the leading-edge radius of the model. For the NACA 23012, $r_{l e}=0.0158 c$. The use of $2 r_{l e}$ as the length scale in eq. (1) instead of chord provides consistency between airfoil and cylinder studies (much of the Langmuir and Blodgett analysis was for cylinders). Note also that this equation can give different values of $K_{0}$ for different airfoil forms even if the chord is the same. Eq. (1) results from using a straight line to approximate the droplet drag $v s$ droplet Reynolds number curve over a portion of the droplet Reynolds number range. This approximation was used to develop equations for icing scaling methods as early as $1955 .^{5} \kappa$ is the slope of this line, and a value of $\kappa=$ 0.38 provides modified inertia parameters sufficiently close to values found from more involved procedures. Equating the scale and reference values of $K_{0}$ gives a practical expression that relates scaled conditions to reference conditions to satisfy droplet trajectory similarity:

$$
\frac{M V D_{S}}{M V D_{R}}=\left(\frac{r_{l e}}{r_{l e}}\right)^{0.62}\left(\frac{p_{S}}{p_{R}}\right)^{.023}\left(\frac{V_{S}}{V_{R}}\right)^{-0.38}
$$

The collection efficiency at the stagnation line, $\beta_{0}$, is uniquely related to $K_{0}$ by the expression given by 
Langmuir and Blodgett:

$$
\beta_{0}=\frac{1.4\left(K_{0}-1 / 8\right)^{0.84}}{1+1.4\left(K_{0}-1 / 8\right)^{0.84}}
$$

When the stagnation-line collection efficiency matches for two geometrically-similar models, so does the collection efficiency everywhere on the model.

Similarity of ice accumulation results from a match of the accumulation parameter, $A_{c}$ :

$$
A_{c}=\frac{L W C V \tau}{2 r_{l e} \rho_{i}}
$$

Finally, the energy balance at the surface can be written following Messinger ${ }^{6}$ in the form,

$$
n=\frac{c_{p, w s}}{\Lambda_{f}}\left(\phi+\frac{\theta}{b}\right)
$$

where $n$ is the freezing fraction; $\phi$, the water energy transfer parameter; $\theta$, the air energy transfer parameter; and $b$, the relative heat factor of Tribus, et al. ${ }^{7}$ The parameters $\phi, \theta$ and $b$ are defined in the following equations.

$$
\begin{aligned}
& \phi=t_{f}-t_{s t}-\frac{V^{2}}{2 c_{p, w s}} \\
& \theta=\left(t_{s}-t_{s t}-r \frac{V^{2}}{2 c_{p}}\right)+\frac{h_{G}}{h_{c}}\left(\frac{p_{w w}-p_{w}}{p}\right) \Lambda_{v} \\
& b=\frac{L W C V \beta_{0} c_{p, w s}}{h_{c}}
\end{aligned}
$$

The convective heat-transfer coefficient, $h_{c}$, in eq. (8) is found from

$$
h_{c}=\frac{1.14 \operatorname{Re}^{.5} \operatorname{Pr}^{.4} k}{2 r_{l e}}
$$

Here $R e$ is based on air properties, on the free-stream velocity, $V$, and on a length of twice the leading-edge radius, $r_{l e}$.

\section{Ruff Scaling Method}

Using combinations of the parameters $K_{0}, A_{c}, n, \phi$, and $\theta$, uuff $^{2}$ performed scaling tests in the AEDC R-1D icing tunnel. He found that the scaled ice shapes agreed best with reference shapes when all five of these scaling parameters were matched to the reference values. This approach to scaling is known as the Ruff (or AEDC) method. Because the R-1D facility allows altitude simulation, Ruff's work included the calculation of the scale test-section pressure in addition to $t_{s t}, M V D, L W C$ and time. With only five scaling parameters to establish these five test conditions, the sixth test condition, scale velocity, was selected arbitrarily. The Ruff method has also been used in sea-level tunnels in a modified form in which $\theta$ is ignored and just $K_{0}, A_{c}, n$, and $\phi$ are matched, with the scale velocity chosen by the user.

In Ruff's experiments, the scale velocity was often simply equated with the reference value. Tests at NASA $^{3,8}$ with large glaze-ice accretions for $n<0.6$ have shown that when the Ruff method with a constant scale velocity was used to determine scale test conditions, the quantity of ice accreted and accretion limits were properly simulated, but features such as horn angle and location were not exactly the same as for the reference ice shape. The best similarity of scaled and reference ice shapes was achieved when the Ruff method was used with an additional similarity parameter, such as the Reynolds number or Weber number, to determine the scale velocity. The use of either of these parameters results in a scale velocity higher than the reference value. For the present study of intercycle ice, the short times between boot activation resulted in small accretions for which features like horns do not have time to develop. Thus, the matching of scale and reference velocities was judged to be an adequate approach.

Note from equation (6) that matching $\phi_{S}$ and $\phi_{R}$, with $V_{S}$ $=V_{R}$, gives $t_{s t, S}=t_{s, R}$. For sea-level tunnels, when velocity is matched, the static pressure will also match, and equation (2) reduces to

$$
M V D_{S}=M V D_{R}\left(\frac{r_{l e S}}{r_{l e R}}\right)^{0.62}
$$

Once the droplet size, $M V D_{S}$, was determined from eq. (10), by solving $n_{S}=n_{R}$ using eqs. (5-9), the liquidwater content, $L W C_{S}$, was found. Finally, eq. (4) gave the scale accretion time from by setting $A_{c S}=A_{c R}$.

\section{Hybrid Scaling}

\section{Description of Hybrid Airfoil Design Method}

The term "hybrid" is used to describe the airfoil that has a nose (or leading-edge) section with full-size airfoil coordinates and a specially designed, truncated, 
afterbody. The basic hybrid design method uses an iterative process to update the contour of the after body until the droplet impingement characteristics and pressure distribution of the common nose section match those of the full-size airfoil. The extent of the common nose section for the present tests is illustrated in figure 1 as an example.

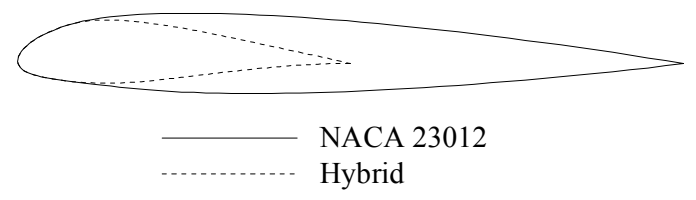

Figure 1. Comparison of Full-Scale NACA 23012 Airfoil with the Hybrid.

The design routine incorporates several analysis tools. For example, for the present study the inviscid flowfield about the airfoil was calculated using the Eppler code. ${ }^{9}$ The droplet trajectories and resulting impingement characteristics were calculated using the AIRDROP code. ${ }^{10}$ The results from both of these codes are known to compare very well with experiments. While the design process was computerized, it did rely on the experience of the designer to make judgments about how well the pressure distributions and droplet impingement characteristics over the common nose section of the two airfoils matched. Saeed ${ }^{11}$ and Saeed, Selig and Bragg ${ }^{12,13,14}$ describe the method in detail and include several illustrative examples.

For this study, the chord length of the hybrid airfoil (36 inches) was $1 / 2$ the desired full-scale NACA 23012 airfoil chord length. The design process used a $40-\mu \mathrm{m}$ water droplet, with the results verified for other sizes. The agreement in impingement curves between the hybrid and full-scale airfoils was generally very good when the droplet size was less than the design value. This was true because as droplet size is reduced, the droplet inertia is also reduced and particles become more responsive to the flowfield. Since the hybrid airfoil was meant to simulate the full-scale airfoil over a $0-4^{\circ}$ angle of attack range, the design procedure used an angle of attack of two degrees. As shown in figure $2(\mathrm{a})$, the local impingement efficiencies, $\beta$, compared very well for this case.

A simple trailing-edge flap was added to achieve better conformity with full-scale at the off-design angles of attack, 0 and $4^{\circ}$. The required flap deflection for $0^{\circ}$ angle of attack was $-3.5^{\circ}$ (upward). With this flap setting at $0^{\circ}$, the agreement between the hybrid and

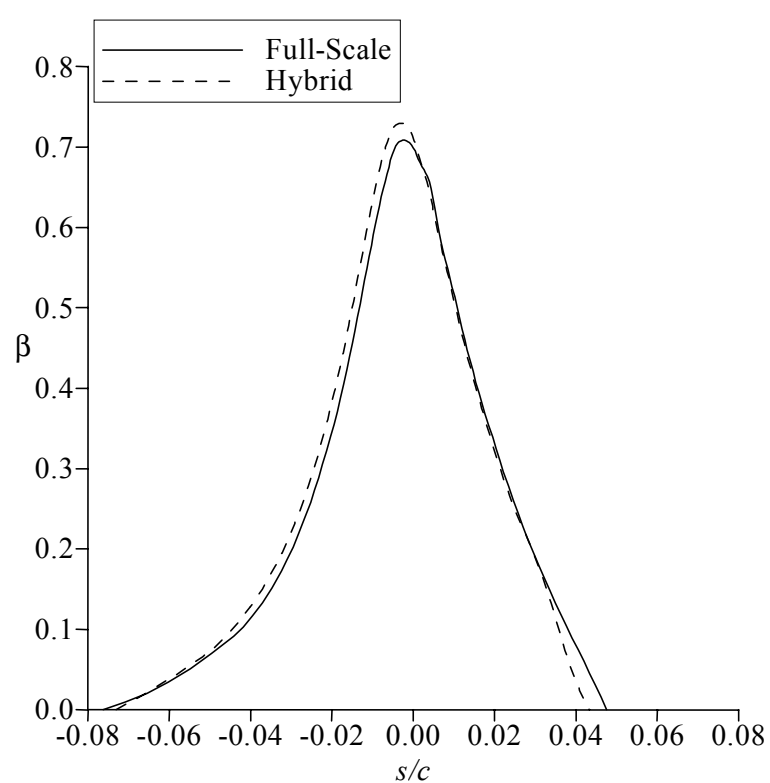

(a) Angle of Attack, $2^{\circ}$.

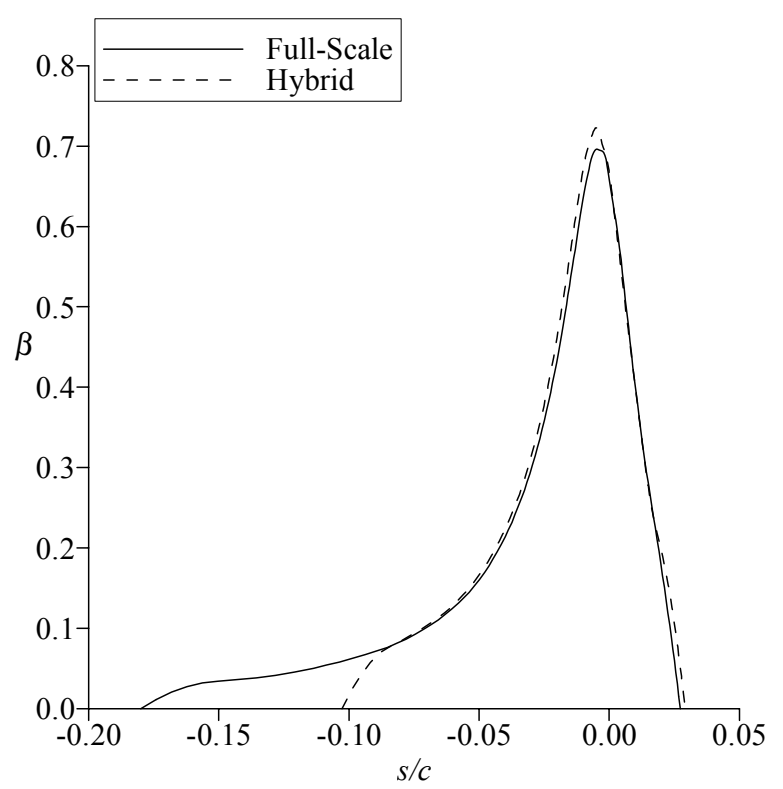

(b) Angle of Attack, $4^{\circ}$; Hybrid Flap Deflection, $2^{\circ}$.

Figure 2. Comparison of the Local Collection Efficiency Between Full-Scale and Hybrid Airfoils. $M V D, 40 \mu \mathrm{m}$.

full-scale collection efficiency was as good over the entire surface as that shown in figure 2(a).

The results for the $4^{\circ}$ case are shown in Fig. 2(b), with a $2^{\circ}$ flap deflection (downward). Again, the agreement was very good everywhere, except for the lower surface impingement limit. The reason for this disparity is that 
the lower-surface limit of the common nose section was not far enough aft to simulate the full-scale impingement. The lower-surface limit of the nose section could have been moved farther aft, but this would have resulted in a much thicker airfoil, which was undesirable (see fig. 1). The difference in the impingement characteristics shown in figure $2(\mathrm{~b})$ is not considered critical since $\beta$ was small (less than 0.1 ) in this region. It should be noted that while maintaining the proper flap setting is important to match the droplet impingement, it might not be critical in determining the final ice shape. This effect is discussed in more detail in reference 14 .

In addition to assisting in the after-body design, the droplet impingement curves were also used to determine the de-icing boot coverage. The approximate limits were $5 \%$ chord on the upper surface and $9 \%$ on the lower surface. (Note that these figures are to the edge of the boot rubber - the active portion of the boot was about one inch upstream of these locations.) For convenience, the upper surface limit of the common nose section was shifted aft to $7.5 \%$ chord and the lower-surface limit was shifted aft to $10 \%$ chord.

\section{$\underline{\text { Scaling Tests }}$}

Two series of tests were performed in the BFGoodrich DSSD IWT to compare results of the Ruff scaling method with the hybrid method for intercycle ice. In the first, a 36-in.-chord NACA 23012 airfoil was used to represent a half-scale model. The second series of tests used a hybrid scaled model to represent the reference, or full-scale, 72-in.-chord NACA 23012 wing section.

\section{Test Facility}

The IWT (fig. 3) is an atmosphericpressure, closed-loop refrigerated tunnel measuring $40 \mathrm{ft}$ by $70 \mathrm{ft}$ overall. It has an external 200-hp electric motor driving a 79-in.-diameter axial fan to provide wind velocity, a 70-ton-capacity refrigeration system for cooling, and two 75-hp air compressors dedicated to supply air for the atomizing nozzles. A honeycomb flow straightener is mounted upstream of the spray bars. There are seven spray bars, heated to prevent water freeze out, with NASA-type spray nozzles to produce the icing cloud. The test section is $22 \mathrm{in}$. wide, 44 in. high, and 60 in. long. Models are typically mounted horizontally between 1-inch-thick aluminum turning plates 30 in. in diameter; these plates can be rotated $360^{\circ}$, even with the tunnel in operation. Access to the model can be attained through two hinged side windows with heated glass panels and a 52-in. section of floor which hinges down to allow full-width access. The bottom door and the ceiling also have heated windows, and unheated acrylic panels can be installed in the turning plates for additional viewing if necessary. The test section is vented to ambient static pressure for baseline pressure measurements.

The IWT can run at speeds from 30 to $230 \mathrm{mph}$, though top speed is limited by temperature, spray time, and percent blockage of the test model. Velocity is measured with a pitot tube located at the entrance to the test section, and is density-corrected for a "true" velocity reading. Temperature in the tunnel is microprocessor-controlled from $-22^{\circ}$ to $+32^{\circ} \mathrm{F}$. It can be held within $\pm 1^{\circ} \mathrm{F}$ of setpoint through most of this range. Spray conditions can be varied from about $0.1 \mathrm{~g} / \mathrm{m}^{3}$ to over $3.0 \mathrm{~g} / \mathrm{m}^{3}$, with droplet sizes from 14 to over 40 microns, depending on velocity and number of nozzles used.

A 4-ft-by-12-ft-by-8-ft cold room, attached to the test section, is available for uses such as casting of ice structures and determining ice adhesion values. The cold room can provide temperatures as low as $-65^{\circ} \mathrm{F}$.

\section{$\underline{\text { Scale Model }}$}

The 36-in.-chord NACA 23012 airfoil used here to represent a scale model is shown in figure 4 . It had a removable leading edge and main body manufactured in aluminum alloy. The leading edge had a nominal recess to allow a flush installation of the pneumatic deicer type $29 \mathrm{~S}$, constructed of 0.085-in.-thick (nominal) rubber and fabric blankets. The de-icer contained five

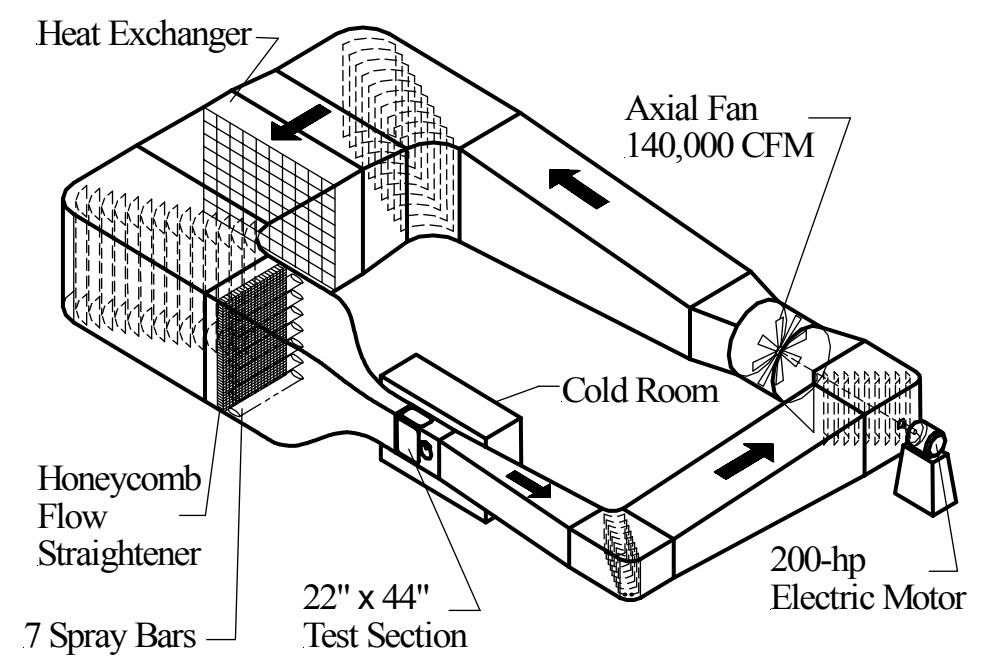

Figure 3. BFGoodrich Aerospace De-icing and Specialty Systems Division Icing Wind Tunnel (IWT). 
spanwise de-icing tubes that inflated during activation. The nominal operating pressure of the pneumatic system was 18 psig.

There are currently no guidelines dealing with boot design or operation for scale tests. Consequently, the same conventional boot tube size was used for both the reference (hybrid) and scale models. Boot inflation and deflation rate characteristics were equivalent for all tests, as well, although times between boot cycles were scaled in the same ratio as the total accretion times as given by the Ruff scaling equations. A thorough scaling study would consider scaling of boot tube sizes and operating characteristics in addition to scaling model size.

\section{Hybrid Model}

The hybrid model also had a chord of 36 in., but the leading edge portion had the same coordinates as a 72-in. NACA 23012 airfoil. It was designed with a removable leading edge (Fig. 5) manufactured in fiberglass with three internal ribs to improve the airfoil stiffness. The main body was manufactured in aluminum alloy with a moveable trailing edge to allow adjustment to the pressure distribution on the leading edge as previously described. The pneumatic deicer was again the $29 \mathrm{~S}$ type integrated into the leading edge as described above, but for the hybrid model, ten spanwise de-icing tubes were used. The nominal operating pressure for the pneumatic de-icer was 20 psig.

Both models were mounted horizontally midway between the IWT ceiling and floor.

\section{De-icing System}

For both tests, two pneumatic de-icing boots were used, with one on the model and one outside the tunnel. This arrangement made it possible to reproduce the inflation rate of a typical airplane de-icer. Supply pressure to inflate the de-icers was obtained from the facility air compressors. The system timer controlled the pressurized air to inflate both of the de-icers simultaneously. A pressure transducer was installed close to the de-icer to provide continuous monitoring of the inlet pressure. When the solenoids were de-energized, an ejector flow control valve provided the vacuum necessary to keep the deicers deflated.
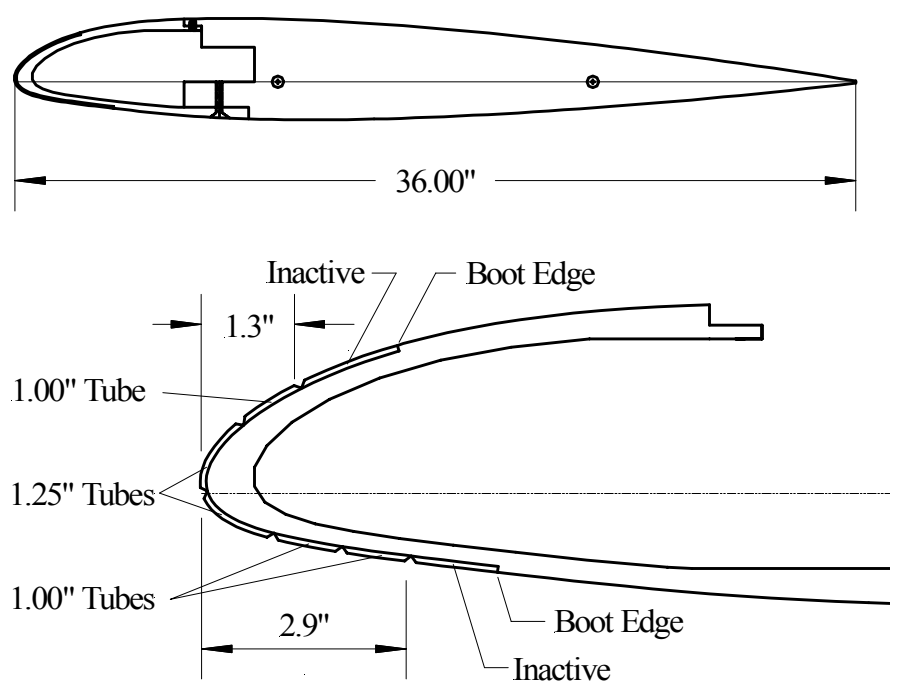

Figure 4. 36-in.-Chord Model of NACA 23012 Wing Section.
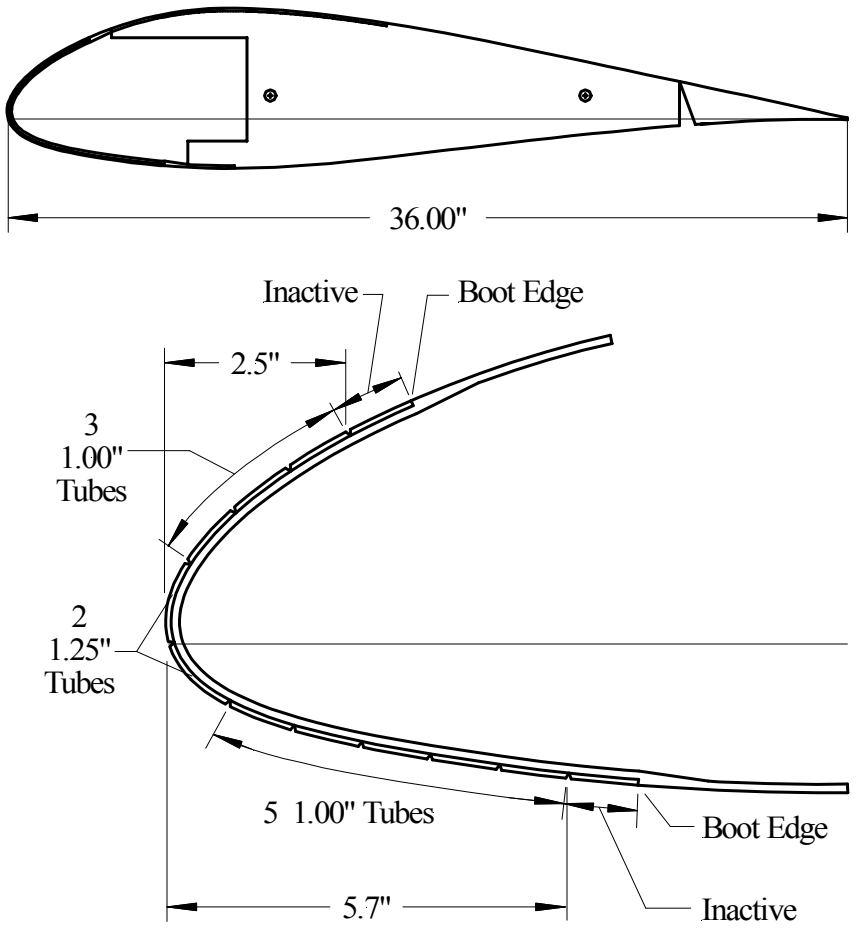

Figure 5. Hybrid Model with Full-Size (72-in.-Chord) NACA 23012 Leading Edge and Truncated After Body.

The inflation-deflation process was controlled electronically and was the same for both models. The boot cycle time (the time between activations) was adjusted for each icing condition to provide a range of intercycle ice accretion sizes. For the scale tests, the boot cycle time was scaled from the reference values in 
the same proportion as the total accretion time. These times were determined by the Ruff scaling method to satisfy $A_{c, S}=A_{c, R}$, with $A_{c}$ defined by eq. (4).

\section{$\underline{\text { Test Procedure }}$}

Prior to each spray, the tunnel airspeed and temperature were stabilized at the desired test values. The spray was then initiated. $L W C$ and $M V D$ reached steady-state within seconds of turning on the nozzles. For each test, the boot was activated to inflate and deflate a few seconds after the start of spray to simulate a justcompleted cycle. Then it was cycled 2 or 3 more times during the spray at the intervals indicated in Table I ("Boot Cycle") to achieve a steady-state with regard to any residual left after multiple de-icer activations. Finally, just before the next scheduled de-icer cycle the spray was shut off to preserve the largest accretion of intercycle ice. The tunnel fan was then stopped, photographs taken of the ice, the cold-room hatch was opened, and the tunnel entered to make a tracing of the ice shape. One, or sometimes two, span-wise location was identified as being typical, or having particularly pronounced features. A thin aluminum plate was heated and applied normal to the model surface at the selected locations to melt a chord-wise groove into the ice down to the airfoil surface. A cardboard template from which the shape of the airfoil leading edge region was cut was then placed into this groove to fit snugly against the clean surface of the wing. Finally, the 2dimensional profiles of the ice-shape features were traced onto these templates with a pencil.
The ice was then cleaned from the model, the hatch closed, and the tunnel, spray bars and deicer controller set to run the next set of conditions.

Ice-shape tracings obtained during the tests were later digitized using automatic line-tracing software. The coordinates were then normalized with respect to the representative chords shown in Table I to permit direct comparison of the reference and scale results.

\section{$\underline{\text { Test Conditions }}$}

Table I lists the test conditions. These test conditions were adjusted for the icing scaling study and some do not reflect conditions within the FAR 25 Appendix C icing envelope. For example, for runs 54/4S, 7/2, 7/3, and $8 / 3$, the combination of temperature, $M V D, L W C$ and duration are outside of (more severe than) the icing envelope. Corresponding reference and scale tests are grouped together in the table. The chords listed are the values consistent with the leading-edge size, which is also the actual model chord for the scale model. For the hybrid model, the value listed in the table is not the true chord of the test model, but rather that which a full NACA 23012 airfoil would have (72 in.) if it had the same leading edge section as the hybrid model.

Angles of attack were 0 and $4^{\circ}$ and static temperatures were 14 and $21^{\circ} \mathrm{F}$. Except for one pair of tests at $175 \mathrm{mph}$, all tests were made with an airspeed of 200 mph. Reference $M V D$ 's were 20 and $31 \mu \mathrm{m}$. Reference $L W C$ 's covered the range of 0.32 to $1.56 \mathrm{~g} / \mathrm{m}^{3}$. Total spray times for the reference case were 8.6 to $34.5 \mathrm{~min}$.

Table I. FAA/BFG Intercycle Ice Tests Scaling Conditions and Similarity Parameters

\begin{tabular}{|r|c|c|c|c|c|c|c|r|r|r|r|r|r|r|r|r|r|}
\hline Run & Date & Model & $\begin{array}{c}c, \\
\text { in }\end{array}$ & $\begin{array}{c}\alpha, \\
{ }^{\circ}\end{array}$ & $\begin{array}{l}t_{s t}, \\
{ }^{\circ} \mathrm{F}\end{array}$ & $\begin{array}{c}t_{\text {tot }} \\
{ }^{\circ} \mathrm{F}\end{array}$ & $\begin{array}{c}V, \\
\mathrm{mph}\end{array}$ & $\begin{array}{c}M V D, \\
\mu \mathrm{m},\end{array}$ & $\begin{array}{c}L W C, \\
\mathrm{~g} / \mathrm{m}^{3}\end{array}$ & $\begin{array}{c}\tau, \\
\mathrm{min}\end{array}$ & $\begin{array}{c}\text { Boot } \\
\mathrm{Cycle}, \\
\mathrm{sec}\end{array}$ & $K_{0}$ & $A_{c}$ & $n$ & $b$ & $\begin{array}{c}\phi, \\
{ }^{\circ} \mathrm{F}\end{array}$ & $\begin{array}{c}\theta, \\
{ }^{\circ} \mathrm{F}\end{array}$ \\
\hline $7 / 5 \mathrm{R}$ & $3-17-00$ & Ref & 72 & 0 & 14.0 & 21.2 & 200.0 & 20 & 0.45 & 12.4 & 181 & 0.73 & 0.14 & 0.56 & 0.32 & 16.3 & 20.5 \\
\hline $8 / 2$ & $3-17-00$ & Ref & 72 & 0 & 14.0 & 21.2 & 200.0 & 20 & 0.45 & 12.4 & 181 & 0.73 & 0.14 & 0.56 & 0.32 & 16.3 & 20.5 \\
\hline $54 / 4 \mathrm{~S}$ & $12-9-99$ & Scale & 36 & 0 & 14.0 & 21.2 & 200.0 & 13 & 0.64 & 4.4 & 64 & 0.74 & 0.14 & 0.56 & 0.32 & 16.3 & 20.5 \\
\hline $8 / 4$ & $3-15-00$ & Ref & 72 & 0 & 14.0 & 21.2 & 200.0 & 31 & 0.32 & 34.5 & 509 & 1.40 & 0.27 & 0.60 & 0.30 & 16.3 & 20.6 \\
\hline $1 / 2$ & $11-30-99$ & Scale & 36 & 0 & 14.0 & 21.2 & 200.0 & 20 & 0.45 & 12.2 & 180 & 1.41 & 0.27 & 0.60 & 0.30 & 16.3 & 20.6 \\
\hline $7 / 2$ & $3-15-00$ & Ref & 72 & 0 & 21.0 & 26.5 & 175.0 & 31 & 1.56 & 8.6 & 170 & 1.29 & 0.39 & 0.13 & 1.32 & 9.7 & 12.0 \\
\hline $45 / 46$ & $12-8-99$ & Scale & 36 & 0 & 21.0 & 26.5 & 175.0 & 20 & 2.20 & 3.0 & 60 & 1.29 & 0.39 & 0.13 & 1.32 & 9.7 & 12.1 \\
\hline $7 / 3$ & $3-15-00$ & Ref & 72 & 4 & 14.0 & 21.2 & 200.0 & 31 & 1.38 & 8.6 & 170 & 1.39 & 0.39 & 0.23 & 1.29 & 16.3 & 20.5 \\
\hline $42 / 44$ & $12-8-99$ & Scale & 36 & 4 & 14.0 & 21.2 & 200.0 & 20 & 1.95 & 3.1 & 60 & 1.40 & 0.39 & 0.23 & 1.29 & 16.3 & 20.5 \\
\hline $8 / 3$ & $3-14-00$ & Ref & 72 & 4 & 21.0 & 28.2 & 200.0 & 31 & 0.46 & 34.3 & 509 & 1.39 & 0.40 & 0.23 & 0.43 & 9.3 & 10.3 \\
\hline $7 / 5$ & $12-1-99$ & Scale & 36 & 4 & 21.0 & 28.2 & 200.0 & 20 & 0.65 & 12.1 & 180 & 1.40 & 0.39 & 0.23 & 0.43 & 9.3 & 10.3 \\
\hline
\end{tabular}


De-icing boot cycle times for the reference case were 170 to 509 sec. Table I also gives the similarity parameters that corresponded with the test conditions for each run. The accumulation parameter given is that based on the boot cycle time.

\section{$\underline{\text { Results }}$}

The intercycle ice that formed on each model exhibited primarily two types of features: (1) an ice cap or main ice structure that accreted at the stagnation line and extended some distance aft on both upper and lower surfaces and (2) feathers that formed at minor discontinuities in the model surface aft of the main ice.

Much of the feather growth began in continuous spanwise rows at the nearly imperceptible stitch lines between the active tubes of the de-icing boots. When these in-line feathers had grown high enough, shedding was observed now and then along portions of the original growth line with new feathers immediately starting to form where the old had been. Thus, the final appearance was that of a number of discrete span-wise segments of ice structures with varying heights above the model surface. In the two-dimensional ice profile tracings, these feather rows had the appearance of protuberances whose size and location often depended on the span-wise location at which the tracing was made.

To determine the variability of intercycle ice accretion, some of the tests were repeated. Figure 6 is a comparison of ice shapes from two repeated tests with the hybrid model. On this and subsequent plots, the upper and lower extents of the active portions of the deicing boots are marked. The boots covered the same portion of the leading edge of both models, relative to the chord corresponding with each model's leadingedge size. Tracings of the ice were taken at locations felt to capture the most prominent features; consequently, centerline positions along the span were not always recorded. In the case of the two results shown in figure 6 , run $7 / 5 \mathrm{R}$ was traced at the center, while $8 / 2$ was traced 2 in left of center. The two tracings showed features of similar size and chord-wise location and generally agreed well.

The random nature of some features due to feather growth and shedding can best be illustrated by looking at variations along the span of the model. The examples in figure 7 were also taken from the hybridmodel tests. Figure 7(a) presents shapes from one of the tests with the longest time between boot firings, 509 sec. Significant features of the ice were able to form in this time. In figure 7(a), the size and shape of the main ice cap can be seen to have been consistent at the two

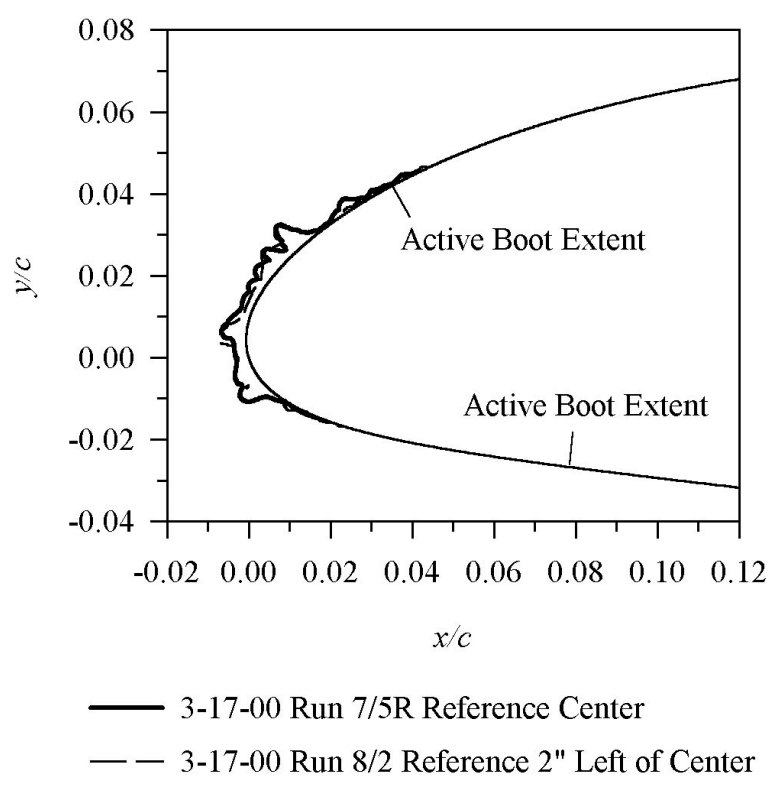

Figure 6. Ice-Shape Repeatability with Hybrid Model. $\mathrm{AOA}, 0^{\circ} ; t_{s t}, 14^{\circ} \mathrm{F} ; V, 200 \mathrm{mph}$; $M V D, 20 \mu \mathrm{m} ; L W C$, $0.45 \mathrm{~g} / \mathrm{m}^{3}$; Time Between De-Icer Cycles, $180 \mathrm{~s}$.

locations, while the size and location of the feathers aft of the main shape were not exactly duplicated. Similarly, for the example given in figure 7(b) the leading-edge accretion and extent of icing were repeated for the two span-wise locations, while the sizes and locations of feather structures were not. Thus, while the main ice shapes repeated well from run to run

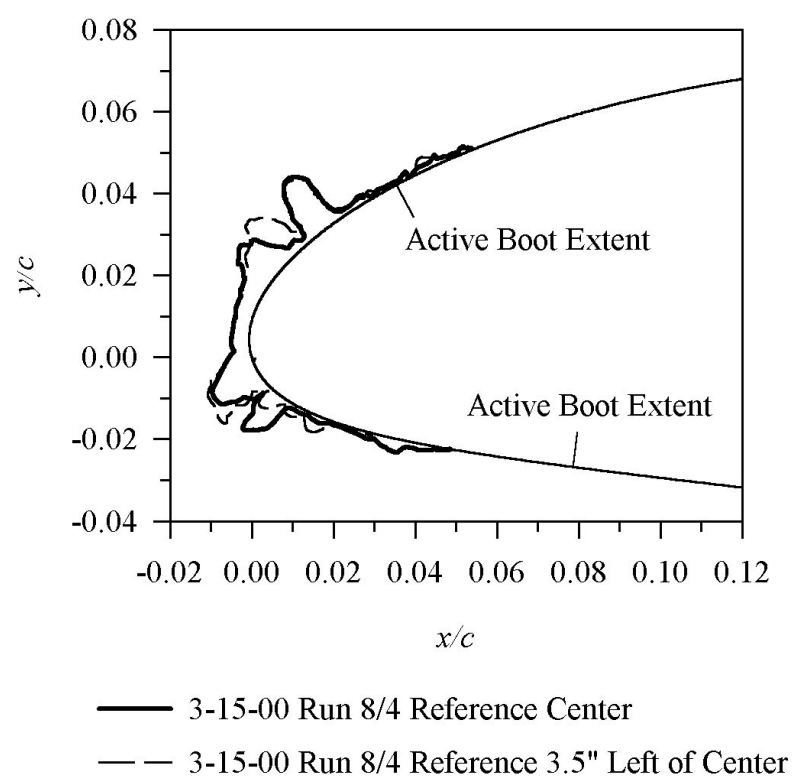

(a) AOA, $0^{\circ}$; tst, $14^{\circ} \mathrm{F} ; V, 200 \mathrm{mph} ; M V D, 31 \mu \mathrm{m}$; $L W C, 0.32 \mathrm{~g} / \mathrm{m}^{3}$; Time Between De-Icer Cycles, $509 \mathrm{~s}$.

Figure 7. Ice-Shape Variation Along the Span. 


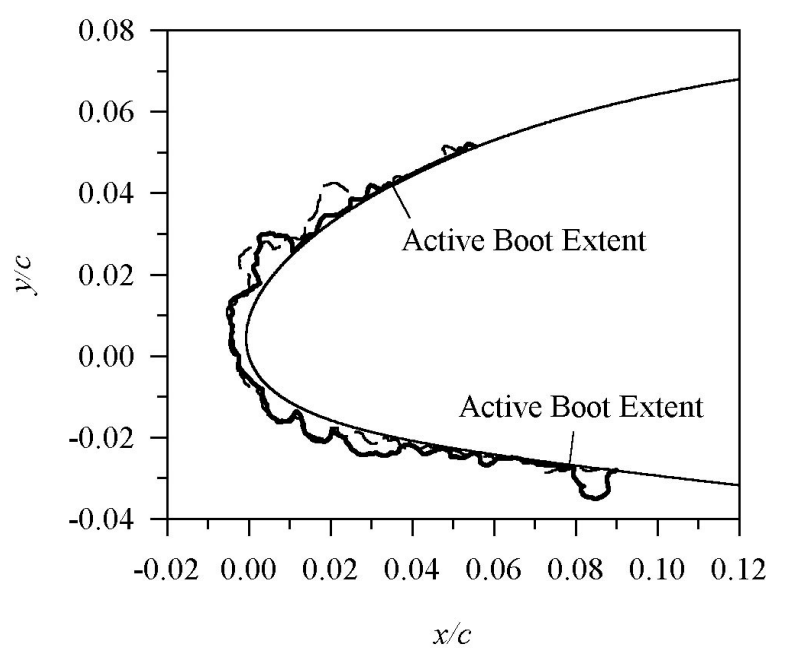

- 3-15-00 Run 7/3 Reference Center

- - 3-15-00 Run 7/3 Reference 2" Left of Center

(b) AOA, $4^{\circ} ; t_{s t}, 14^{\circ} \mathrm{F} ; V, 200 \mathrm{mph} ; M V D, 31 \mu \mathrm{m}$; $L W C, 1.38 \mathrm{~g} / \mathrm{m}^{3}$; Time Between De-Icer Cycles, $170 \mathrm{~s}$.

Figure 7 (concluded).

for a given model, protuberances aft of the main shape were typically random in size and location, primarily due to feather shedding and regrowth.

The two models used in this study were designed with objectives other than scaling. Consequently, the same boot tube size was used for both the reference and scale model. Because the hybrid (reference) model contained twice as many deicer tubes as the scale model (see figures 4 and 5), the reference model produced more rows of feathers over the boot than did the scale model. Thus, the scale tests could not be expected to simulate the location of these feather rows adequately.

Figure 8 gives examples of the scaling results. Figures $8(\mathrm{a})$, (b) and (c) show results obtained at $0^{\circ} \mathrm{AOA}$, while $8(\mathrm{~d})$ and (e) are for $4^{\circ}$ AOA. In general, the scale test accurately simulated the thickness of the leadingedge ice and chord-wise extent of icing. Successful scaling of these two characteristics indicates that the accumulation parameter, $A_{c}$, and modified inertia parameter, $K_{0}$, were properly matched in determining the scale conditions.

In figure 8(a), it can be seen that the scale test produced ice without some of the feather structures seen in the reference. From the above discussion, this result is not surprising. However, even in the stagnation region, the scaled ice lacked some of the reference-ice protuberances, giving the scaled ice a generally smoother appearance. The reasons for this smoother

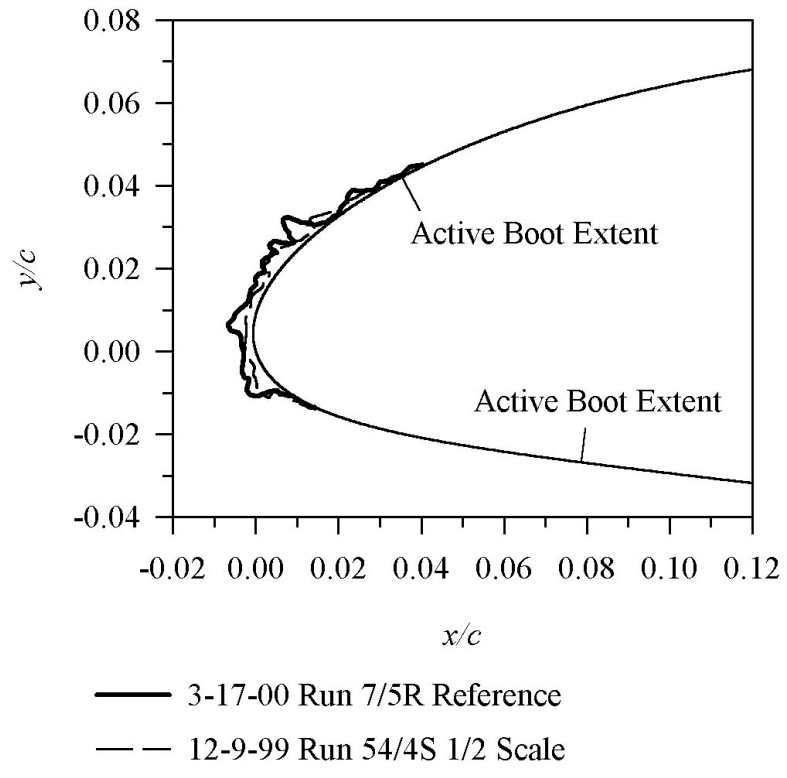

(a) Ice Accretions for Runs $7 / 5 \mathrm{R}$ (Reference) and 54/4S (Scale). AOA, $0^{\circ}$.

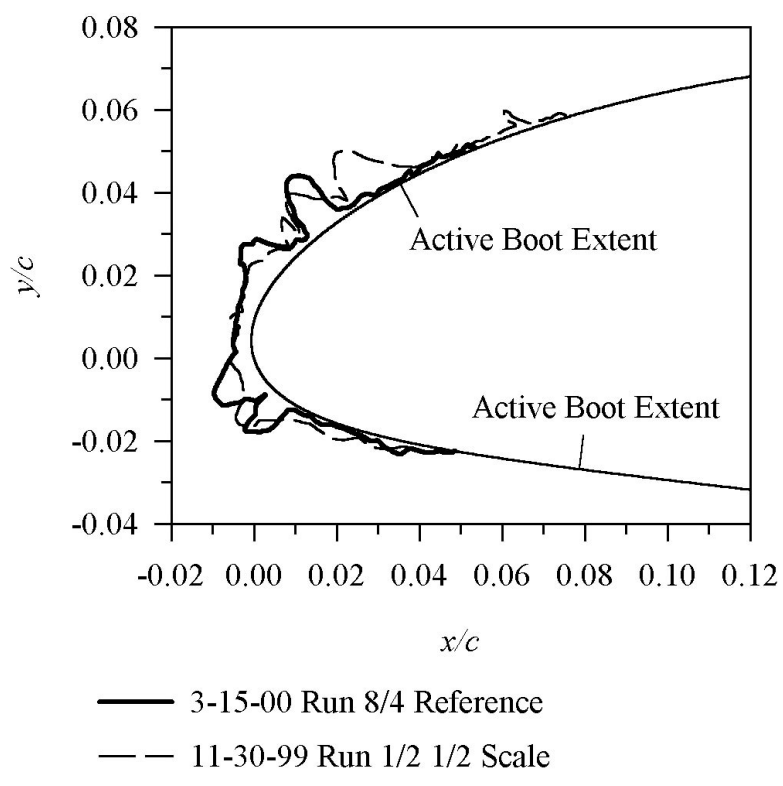

(b) Ice Accretion for Runs 8/4 (Reference) and 1/2 (Scale). AOA, $0^{\circ}$.

Figure 8. Comparison of Reference and Scale Ice Shapes. NACA 23012 Airfoil; Reference Chord, 72 in.; Scale Chord, 36 in. Test Conditions for each Run Listed in Table I.

ice are not understood at this time, but the possible effect of the boot inflation-deflation characteristics should be considered. A rigorous scaling test would 


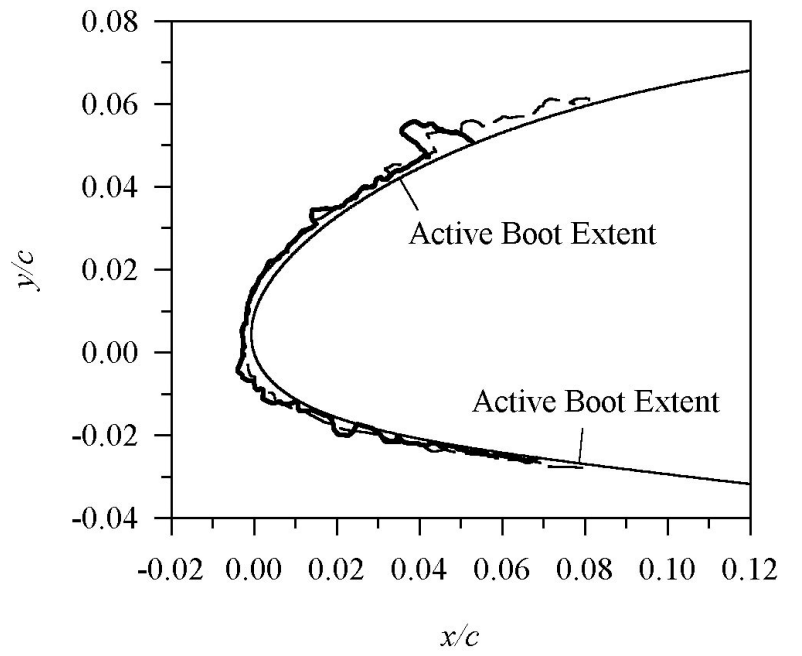

- 3-15-00 Run 7/2 Reference
- - 12-8-99 Run 45/46 1/2 Scale

(c) Ice Accretions for Runs 7/2 (Reference) and 45/46 (Scale). AOA, $0^{\circ}$.

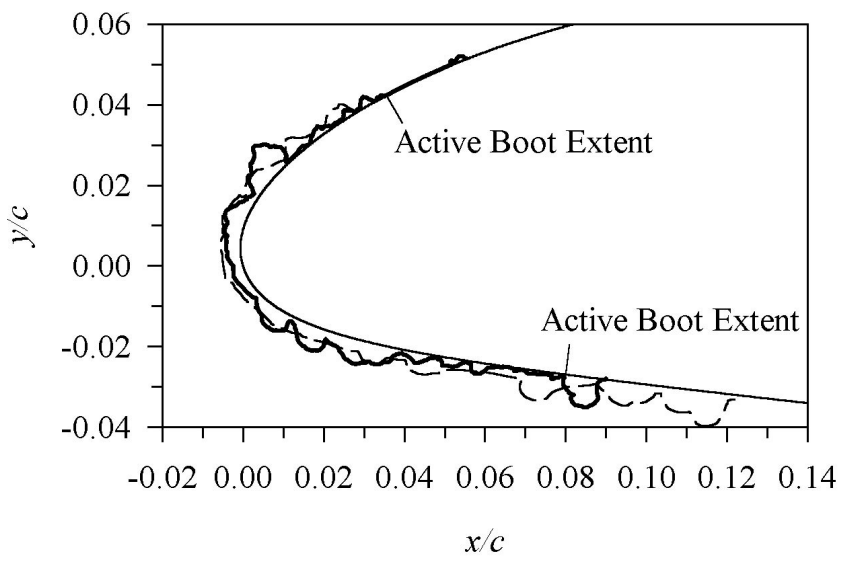

- 3-15-00 Run 7/3 Reference
- 12-8-99 Run 42/44 1/2 Scale

(d) Ice Accretion for Runs 7/3 (Reference) and 42/44 (Scale). AOA, $4^{\circ}$.

Figure 8. (con’t.)

include scale and reference model designs for which all physical features, including boot tube sizes, have the correct scale, and boot inflation, dwell and deflation times would also be scaled. For the present tests, this rigor was not applied.

The results shown in figure $8(\mathrm{~b})$ give an example for which both the size and approximate position of the feather structures of the reference were simulated by the scale test. However, the small horns at the sides of the

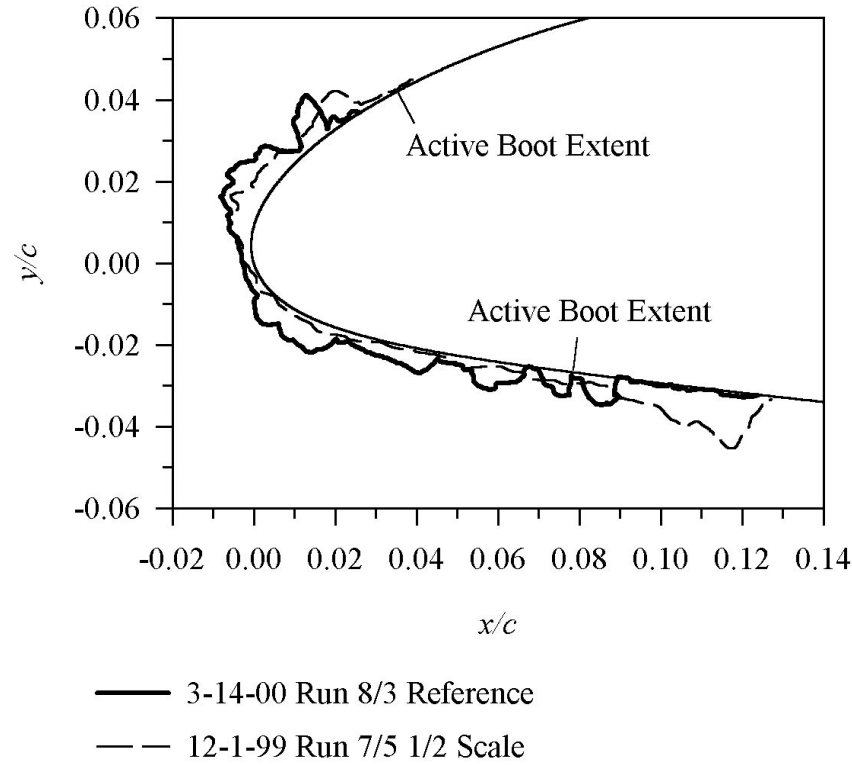

(e) Ice Accretions for Runs $8 / 3$ (Reference) and 7/5 (Scale). AOA, $4^{\circ}$.

Figure 8. (concluded).

main ice shape in the reference test were missing from the scale results, so the match of shapes is not exact.

For the examples in figure 8(c) the scale and reference shapes generally matched in thickness over the active boot surface, while the scaled shape showed fewer rows of feathers. The aft edge of the inactive boot material joined the model skin at $x / c=0.05$ on the upper surface of the reference model, and the profile of a row of large feathers can be seen at this location. This joint was at $x / c=0.08$ for the scale model, and small feathers were formed forward of this surface discontinuity as well.

At $4^{\circ}$ AOA (figs. 8(d) and (e)) the lower-surface accretion limit for the $1 / 2$-scale model extended farther aft than for the reference (hybrid) model. It is interesting to note from figure 2(b) that the lowersurface impingement limit for a full-size 72-in.-chord NACA 23012 airfoil was also predicted to be farther aft than that for the hybrid model. Thus, for the $4^{\circ} \mathrm{AOA}$ tests the hybrid model aft of the lower-surface active boot region may not have adequately represented a fullsize reference model, and ice-accretion characteristics cannot be meaningfully compared for the two test models in that region.

As with the $0^{\circ} \mathrm{AOA}$ tests, the scale tests showed fewer rows of feathers than the reference tests, and the main ice was smoother for the scale test. The scale tests did simulate the sizes of the feather structures reasonably well. Figures 8(d) and (e) show rows of feathers near 
the lower-surface boot termination for both the reference $(x / c=0.09)$ and scale $(x / c=0.12)$ models. Because the boots extended farther relative to the chord for the scale model, the feathers formed for the two models were understandably in different positions.

\section{Summary and Conclusions}

The Ruff method with matched scale and reference velocity was used to determine appropriate $1 / 2$-scale test conditions to simulate a full-size icing encounter for an NACA 23012 wing section protected with a pneumatic boot de-icing system. Intercycle ice accretions were recorded on a 36-in.-chord model that represented $1 / 2$ scale and compared with those on a reference model (a hybrid with a full-size leading-edge and truncated aft section) representing a full-size 72-in.-chord airfoil. Relative to the chord, the intercycle ice thickness and extent of icing for the $1 / 2$-scale tests generally compared well with those from the reference model. However, the scale tests typically produced ice with fewer rows of feathers. These results appear to be due to the use of twice the number of de-icing boot tubes for the reference model than for the scale. Smoother ice also resulted for the scale model in the stagnation region. While the reason for this difference is not understood at this time, it may be the result of not scaling the boot inflation, dwell and deflation times along with the model size.

Although the tests reported here did not demonstrate fully successful scaling, the differences between the scale and reference results appeared to be linked primarily to the differences in the relative sizes of the pneumatic tubes used for the two models. Further scaling studies are needed in which boot tube sizes and operating characteristics are both scaled with model size. It is likely that with properly scaled ice-protection systems, scale models-using either full geometric scaling or hybrid scaling-can be used to predict intercycle ice accretion characteristics of larger models.

\section{$\underline{\text { References }}$}

${ }^{1}$ Charpin, Francois and Fasso, Guy, "Icing Testing in the Large Modane Wind Tunnel on Full Scale and Reduced Scale Models," L'Aeronautique et l'Astronautique, no. 38, 1972. English translation published as NASA TM-75373, March 1979.

2 Ruff, G.A.: "Analysis and Verification of the Icing Scaling Equations," AEDC-TR-85-30, vol. 1 (Rev), March 1986.
3 Anderson, David N. and Ruff, G.A., "Evaluation of Methods to Select Scale Velocities in Icing Scaling Tests," AIAA-99-0244, January 1999.

4 Langmuir, Irving and Blodgett, Katharine B.: "A Mathematical Investigation of Water Droplet Trajectories," Army Air Forces Technical Report No. 5418, February 1946.

5 Sibley, E.J. and Smith, R.E., "Model Testing in an Icing Wind Tunnel," Lockheed Aircraft Corporation, California Division, Report LR10981, October 1955.

6 Messinger, B.L., "Equilibrium Temperature of an Unheated Icing Surface as a Function of Airspeed," J. Aeron. Sci. vol. 20 no. 1, January 1953, pp. 29-42.

${ }^{7}$ Tribus, Myron, Young, G.B.W. and Boelter, L.M.K., "Analysis of Heat Transfer Over a Small Cylinder in Icing Conditions on Mount Washington," Trans. ASME vol. 70, November 1948, pp. 971-976.

8 Anderson, David N., "Effect of Velocity in Icing Scaling Tests," AIAA-2000-0236, January 2000.

9 Eppler, R., "Direct Calculation of Airfoils from Pressure Distribution," NASA TT F-15, 417, March 1974. (Translated from Ingenieur-Archive, vol. 25, no. 1, 1957, pp. 32-57).

${ }^{10}$ Bragg, M.B., "Rime Ice Accretion and Its Effect on Airfoil Performance," Ph.D. Dissertation, Dept. of Aeronautical and Astronautical Engineering, Ohio State Univ., Columbus, OH, 1981; also NASA CR-165599, March 1982.

${ }^{11}$ Saeed, F., "Hybrid Airfoil Design Methods for FullScale Ice Accretion Simulation," Ph.D. Dissertation, Dept. of Aeronautical and Astronautical Engineering, Univ. of Illinois at Urbana-Champaign, Urbana, IL, Jan. 1999.

${ }^{12}$ Saeed, F., Selig, M.S., and Bragg, M. B., "Design of Subscale Airfoils with Full-Scale Leading-Edges for Ice Accretion Testing," J.Aircraft, vol. 34, no. 1, 1997, pp. 94-100.

13 Saeed, F., Selig, M.S., and Bragg, M. B., "Hybrid Airfoil Design Method to Simulate Full-Scale Ice Accretion Throughout a Given $\alpha$ Range," J. Aircraft, Vol. 35, No. 2, 1998, pp. 233-239.

14 Saeed, F., Selig, M.S., and Bragg, M. B., "Hybrid Airfoil Design Procedure Validation for Full-Scale Ice Accretion Simulation," J. Aircraft, vol. 36, no. 5, 1999, pp. 769-776. 


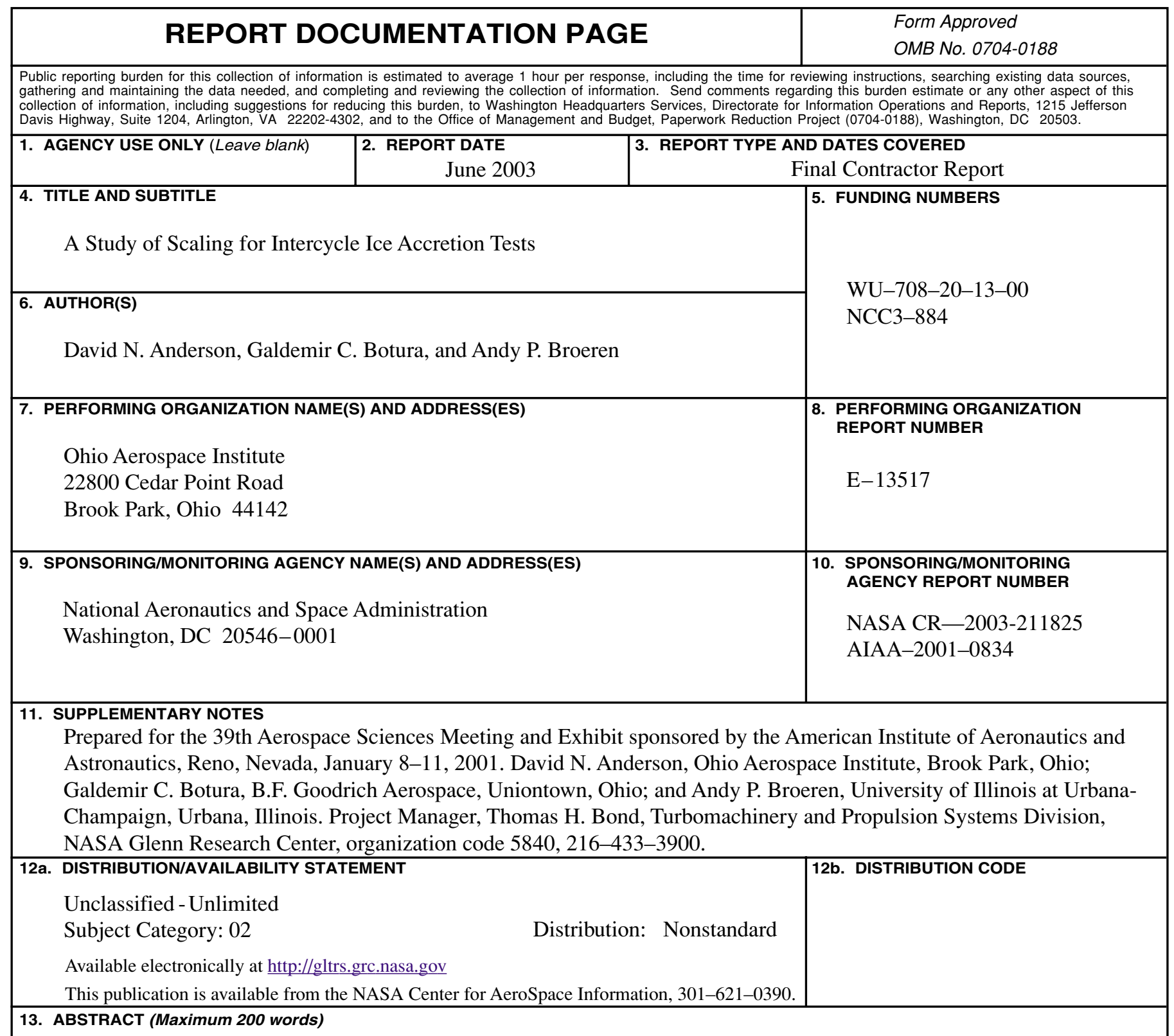

The Ruff method with matched scale and reference velocity was used to determine appropriate 1/2-scale test conditions to simulate a full-size icing encounter for an NACA 23012 wing section protected with a pneumatic boot deicing system. Intercycle ice accretions were recorded on a 36-in-chord model used to represent 1/2-scale and compared with a hybrid reference model (full-size leading-edge and truncated aft section) representing a 72-in-chord full-size airfoil. The intercycle ice thickness and extent of icing for the scale tests generally compared well with those from the reference model. However, the scale tests did not reproduce the location and number of feather rows seen in the reference tests aft of the main ice shape. Many of the differences observed were believed to result from not scaling the pneumatic boot design along with the model size for these tests.

\begin{tabular}{|c|c|c|c|}
\hline \multicolumn{3}{|l|}{ 14. SUBJECT TERMS } & \multirow{2}{*}{\begin{tabular}{|c|} 
15. NUMBER OF PAGES \\
17 \\
\end{tabular}} \\
\hline \multicolumn{3}{|c|}{ Aircraft safety; Aircraft icing; Ice-protection systems; Icing scaling } & \\
\hline $\begin{array}{l}\text { 17. SECURITY CLASSIFICATION } \\
\text { OF REPORT }\end{array}$ & $\begin{array}{l}\text { 18. SECURITY CLASSIFICATION } \\
\text { OF THIS PAGE }\end{array}$ & $\begin{array}{l}\text { 19. SECURITY CLASSIFICATION } \\
\text { OF ABSTRACT }\end{array}$ & 20. LIMITATION OF ABSTRACT \\
\hline Unclassified & Unclassified & Unclassified & \\
\hline
\end{tabular}

